\title{
BMJ Global Health Is water carriage associated with the water carrier's health? A systematic review of quantitative and qualitative evidence
}

\author{
Jo-Anne Lee Geere, ${ }^{1}$ Moa Cortobius, ${ }^{2}$ Jonathan Harold Geere, ${ }^{3}$ \\ Charlotte Christiane Hammer, ${ }^{1}$ Paul R Hunter ${ }^{1,4}$
}

To cite: Geere J-AL,

Cortobius M, Geere $\mathrm{JH}$, et al. Is water carriage associated with the water carrier's health? A systematic review of quantitative and qualitative evidence. BMJ Glob Health 2018;3:e000764. doi:10.1136/ bmjgh-2018-000764

Handling editor Seye Abimbola

- Additional material is published online only. To view, please visit the journal online (http://dx.doi.org/10.1136/ bmjgh-2018-000764).

Received 9 February 2018 Revised 14 May 2018 Accepted 17 May 2018

Check for updates

${ }^{1}$ Faculty of Medicine and Health Sciences, University of East Anglia, Norwich, UK ${ }^{2}$ Stockholm International Water Institute, Stockholm, Sweden ${ }^{3}$ Physiotherapy Department, Spire Hospital, Norwich, UK ${ }^{4}$ Department of Environmental Health, Tshwane University of Technology, Pretoria, South Africa

Correspondence to Dr Paul R Hunter; paul.hunter@uea.ac.uk

\section{ABSTRACT}

Introduction The work of carrying water falls mainly on women and children, particularly in sub-Saharan Africa and rural areas. While concerns have been raised, how water carriage is associated with health of the water carrier is not clear. The aim of this review is to summarise evidence on whether, and how, water carriage is associated with the water carrier's health.

Methods A systematic review of literature was conducted, searching Embase; Medline; Web of Science Social Sciences Citation Index; Web of Science Arts and Humanities Citation Index; International Initiative for Impact Evaluation website; WHO Virtual Health Sciences Library and WHO African index medicus, from inception to 8 November 2017.

Results Forty-two studies were included. Their ability to demonstrate cause and effect relationships was limited by study design and fair or poor methodological quality. Overall, the studies suggest that water carriage is associated with negative aspects of the water carriers' health. There is moderate quantitative and strong qualitative evidence that water carriage is associated with pain, fatigue, perinatal health problems and violence against vulnerable people, and inconclusive evidence of an association with stress or self-reported mental health and general health status.

Conclusion In many circumstances, water carriage is a potential barrier to Sustainable Development Goal (SDG) 6 target 'universal and equitable access to safe and affordable drinking water for all' and SDG 3 'ensure healthy lives and promote well-being for all at all ages'. Efforts should focus on providing water on premises, and where this is not possible, providing water close to home and reducing risk of gender-based violence.

\section{INTRODUCTION}

Historically, the focus of water and health research has been on management of water quality and risk or prevalence of infectious disease. However, health is defined more broadly as 'a state of complete physical, mental and social well-being and not merely the absence of disease or infirmity'. "More recently, interest in the work of carrying water

\section{Key questions}

What is already known?

- Water carriage work falls mainly on women and children, particularly in sub-Saharan Africa and rura areas.

- Water is often carried in addition to other loads, and it may not be the heaviest or key porterage task leading to health issues.

\section{What are the new findings?}

- Moderate quantitative and strong qualitative evidence indicates that water carriage is associated with pain, fatigue, perinatal health problems and violence against vulnerable people, while the evidence that water carriage is associated with stress and general health is inconclusive.

What do the new findings imply?

- Efforts to improve access to safe drinking water should focus on achieving 'safely managed' water on premises.

- Where water fetching must continue, strategies to reduce risk of harm should focus on providing water close to home and reducing risk of gender-based violence.

from sources located away from the home, or 'off-plot', has been raised by WHO, Unicef ${ }^{2} 3$ and the International Labour Organisation. ${ }^{4}$ Understanding how water carriage is associated with health is relevant to the United Nations Sustainable Development Goal (SDG) 6, target 1 'universal and equitable access to safe and affordable drinking water for all', 5 and SDG 3, which aims to ensure 'healthy lives and promote well-being for all at all ages'. ${ }^{6}$ Adverse health impacts of water carriage are likely to have implications for SDGs 1 (end poverty in all its forms), 4 (quality education), 5 (gender equality), 8 (decent work and economic growth), 10 (reduced inequalities) and 16 (promote peaceful and 
inclusive societies). ${ }^{7}$ They would also make water access inequitable for those obtaining water off-plot compared with people with safe water piped into their homes, and directly create inequity in relation to SDG 3.

Previous research has demonstrated an association between distance or time to water source and health of children in the home, as indicated by diarrhoeal disease, and child anthropometrics and mortality. ${ }^{8-10}$ Stelmach and Clasen ${ }^{11}$ reviewed the association between water quantity and health. In low-income countries, incidence of trachoma and gastrointestinal-related disease improved with increased quantity of water in the home, and in high-income countries, higher levels of water consumption were associated with renal and bladder cancer, but not type II diabetes. What is absent from these studies of distance to water source and increased household water quantity, is investigation of how these factors affect the health of the person who brings water into the home. It is clear that women and children most commonly collect and carry water home for household use, ${ }^{3} 1213$ often by carrying 20-25 L containers on their head ${ }^{14}$ or by other methods such as loading a number of containers into a wheelbarrow. ${ }^{15}{ }^{16}$ While concerns have been raised, what remains unclear, is how the work of water carriage is associated with the health of the water carrier. With more attention focused on this issue in recent years, a review of the published literature to summarise what is currently known and identify gaps in the existing knowledge base is timely. Therefore, a systematic review of published literature was conducted with the aim of answering the review question: 'Is the work of water carriage associated with the health of individuals who fetch and carry water for household use?'

\section{METHODS}

A systematic review of literature was undertaken to identify research investigating the relationship between water carriage and health.

\section{Search strategy and selection criteria}

A search of electronic databases was conducted from inception to 8 November 2017 by one reviewer (JLG). Seven electronic databases were accessed: Embase; Medline; Web of Science Social Sciences Citation Index selecting public, occupational and environmental health themes; Web of Science Arts and Humanities Citation Index; grey literature databases provided by the International Initiative for Impact Evaluation (http://www. 3ieimpact.org/), the WHO Virtual Health Sciences Library (www.emro.who.int/information-resources/ vhsl/) and the WHO African index medicus. Experts in the field of water access and health were also contacted to identify relevant literature and reference lists of included papers were checked for relevant papers.

One researcher (JLG) independently exported titles and abstracts of all retrieved citations into endnote (X7) and removed duplicates. Retrieved titles and abstracts were evaluated against predefined inclusion criteria by two reviewers (JLG and PRH). Studies were included in the review if they reported quantitatively measured variables or qualitative reports related to the work of fetching water from an off-plot or out of home source and carrying it back home and included some measurement or qualitative appraisal of the health of the person who performed the water carriage work. Studies were excluded if they did not present any quantitative or qualitative analysis of the relationship between water carriage and health of people who perform water carriage work.

\section{Inclusion criteria}

- Quantitative research reporting the relationship between variables related to the physical work of carrying filled water containers and variables related to the health of the water carrier.

- Qualitative research where people who carry water report the effect of water carriage on their own health or the health of others who carry water.

- Studies reported in English, French, Spanish, Portuguese, Swedish or Turkish.

\section{Exclusion criteria}

- Studies reporting health only of children aged 5 or less, because children of this age are much less likely to carry significant water for household use.

- Studies reporting variables related to water access and water carrying, but not reporting health of the water carrier other than prevalence or indicators of infectious or vectorborne diseases.

- Article with a topic focus on sanitation, hygiene, water source type and water source or household water contamination or treatment, without data on the work of water carriage and health of water carriers.

- Article with information on 'water insecurity' and health, without any data about the association between physically carrying water containers (as an aspect of water security) and health, disaggregated from other aspects of water insecurity (such as limited water quantity or quality).

Advanced searches were conducted using key terms combined with boolean operators to maximise search sensitivity. Terms were also mapped to medical subject headings (MeSH) in Medline and Embase. Truncation terms and searches in all fields '.af' were used to maximise search sensitivity in each database where possible (online supplementary appendix 1).

\section{Data analysis}

Summary measures, statistics and qualitative themes reported in the studies were diverse, and findings are presented as reported in each study. Where studies separately presented analyses of multiple risk factors or independent variables, and multiple outcomes or dependent variables, only findings which reported the relationship between variables related to the work of water carriage and health outcomes of the water carrier were extracted. 
No studies were excluded on the basis of methodological quality, which was appraised independently by two reviewers: JLG and $\mathrm{CH}$ for qualitative aspects of studies, and JLG and JHG for quantitative aspects of studies. Where differences in quality scores could not be agreed, a third reviewer (PRH) was consulted to achieve consensus. The US Department of Health and Human Services, National Institutes of Health (NIH) Quality Assessment tool for observational cohort and cross-sectional studies ${ }^{17}$ was used for 26 studies which reported quantitative data, and the Critical Appraisal Skills Programme (CASP) tool $^{18}$ was used for 21 studies which were qualitative or of mixed methods and reporting a qualitative component to the study.

Meta-analysis was planned. However, the studies included in the review were too heterogeneous to perform a meta-analysis, because of differences in the characteristics of study samples, and exposure variables or outcomes measured, therefore a narrative synthesis was completed. A wide variety of systems to grade the strength of evidence gathered in systematic reviews have been reported, however most place emphasis on a hierarchy of research design considered most robust for determining the effectiveness of a clinical intervention. ${ }^{19}$ We therefore used a system reported by Hoogendoorn et $a l,{ }^{20}$ to rate the strength of evidence from observational cohort and case-referent studies, considering study quality, number and consistency of findings. We modified the approach by Hoogendoorn et al by applying it to the synthesis of cross-sectional and qualitative studies, and incorporating the NIH and CASP ratings of study quality, because we aimed to identify whether water carriage is associated with reported health problems, even if it were not possible to establish a cause and effect relationship. There was no funding source for this study.

\section{RESULTS}

Nineteen thousand, seven hundred and fifty-eight titles were retrieved through the electronic database searches (figure 1). Once duplicates were removed, 12131 articles remained for further screening of abstracts and titles against the inclusion and exclusion criteria. Of these, 11 789 articles were excluded (305 remained), because the title and abstract clearly indicated that the content was irrelevant to the purpose of this review; or because health outcomes were reported only for children aged 5 years or less or for cases of infectious disease; or they reported only sanitation and hygiene practices or household water supply type without information about water source location (ie, does not indicate need for water fetching work). A further 37 papers were flagged electronically while retrieving full-text papers from the databases, identified in reference lists of retrieved papers or obtained from contacting water, sanitation and hygiene (WASH) experts.

In total, the full text of 342 articles was obtained for review against the inclusion and exclusion criteria. Of these, 300 were excluded because they did not include data on either the work of water fetching or health of water carriers or both. Articles which focused on the health impact of physical contact with water at the point of collection, for example, reporting prevalence of schistosomiasis infection and observed or reported water contact time during water fetching activities, were also excluded because such studies do not provide information on the association between health and the work of carrying water containers home. In total, 42 articles were included in the review, which reported associations with the health of water carriers and the work of water carriage.

Twenty-six studies collected quantitative data. ${ }^{1421-45}$ The overall methodological quality of the studies, in terms of their capacity to demonstrate a cause and effect relationship between the work of water carriage and health was rated as fair (6 studies) or poor (19 studies), only one was rated as good (table 1). The key reasons for low-quality ratings were the use of cross-sectional study design, lack of evidence to support the reliability and validity of exposure or outcome measures, lack of outcome assessor blinding and failure to include confounding factors in analyses.

Twenty-one studies reported qualitative data $^{2326313234354446-59}$ (table 2). While almost all seemed to have appropriately chosen a qualitative research design to meet their aims and provided a clear statement of research findings, there was often insufficient information reported to determine whether recruitment, data collection and analysis were appropriate and sufficiently rigorous. The influence of the researcher and ethical issues were also not clearly reported in most of the studies. We rated studies as 'good' if six or more of the appraisal criteria scored a 'yes' response, fair if four or five criteria had yes responses and poor if three or fewer had yes responses. The scoring process resulted in 12 of the studies being rated as of good quality, 5 of fair quality and 4 rated as poor quality.

The articles reported health and social outcomes including bodily pain, energy expenditure or fatigue, stress or mental well-being, perinatal health and access to healthcare services, lack of safety or discrimination related to social vulnerability and general health status. The studies reporting social outcomes of safety and discrimination were included because of the clear and likely direct impact of the reported social factors on the water carrier's physical or psychological health. The reported health outcomes are grouped for comparison under key themes: bodily pain, energy expenditure and fatigue, stress and mental well-being, perinatal health, social vulnerability and general health.

There is moderate evidence from quantitative data and strong evidence from qualitative data of an association between water carriage and self-reported pain or injury (tables 3 and 4). Sixteen reports of 15

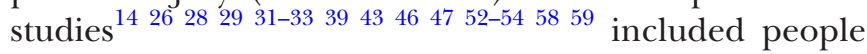
within their study samples whose experience of water 


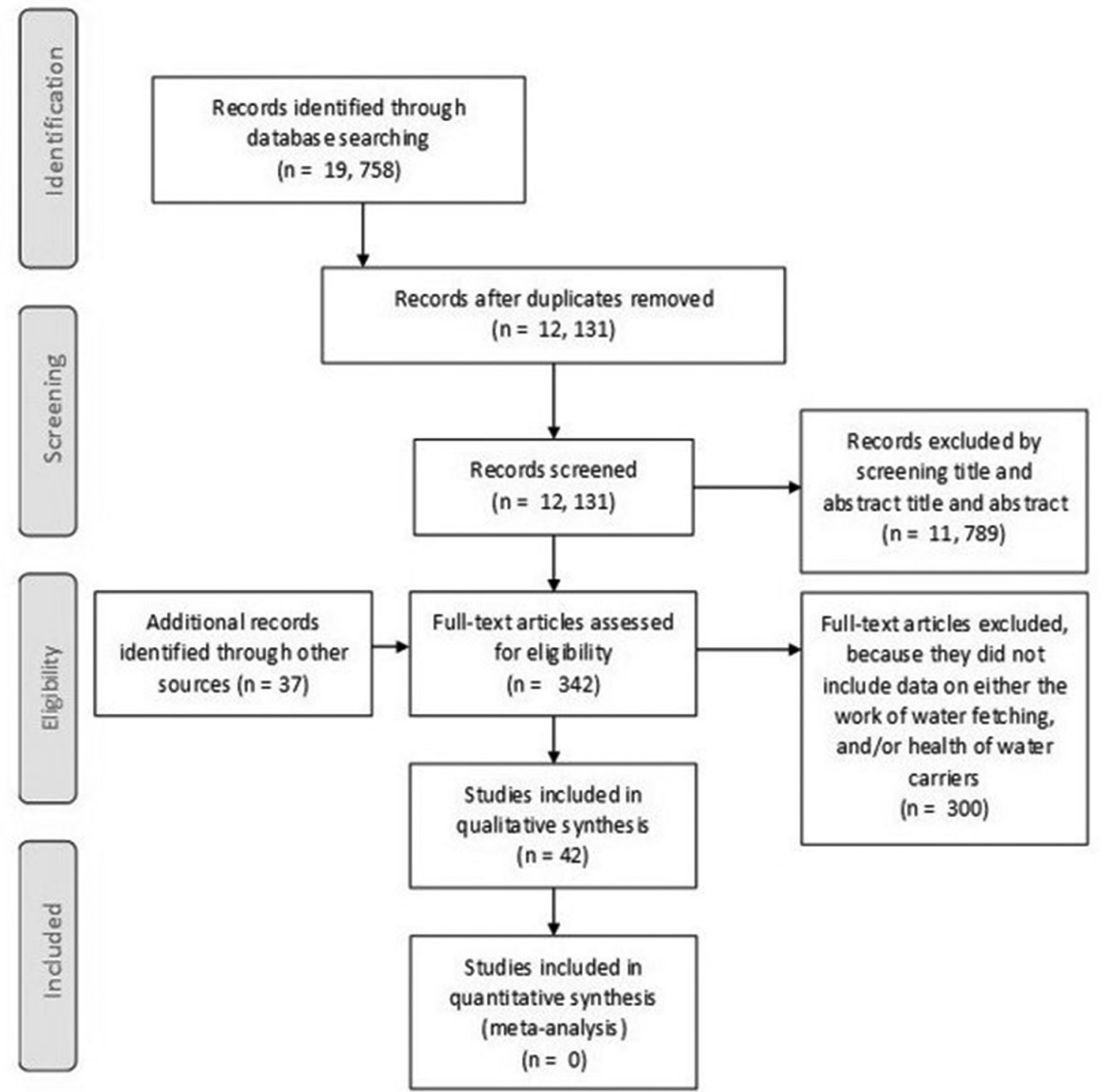

Figure 1 Study selection (Preferred Reporting Items for Systematic Reviews and Meta-Analyses 2009).

carriage was associated qualitatively, or through quantitative analysis, with pain, injury or risk of injury (table 5). The significantly reduced distance walked and time spent for water fetching among head-loading water carriers who reported pain, compared with those who did not report pain, was interpreted by Geere $e t a l,{ }^{14}$ as an indication of pain-related disability. They suggested that people who experienced pain during water fetching may reduce the length of time they are exposed to the loading force, while those without pain or with lower levels of pain may be able to collect water from greater distances. Although their study was limited by a small sample size, their findings are supported by the studies including qualitative data derived from people who collect water. They are also supported by the findings of Rauniyar et al, ${ }^{29}$ who attributed a significant 5\% reduction in the 'drudgery' of water fetching among the lowest socioeconomic group to water supply projects, and the findings of Porter et $a l^{60}$ who found high proportions of children reporting pain as a direct result of load-carrying, which particularly for girls, included water carriage by head loading. However, as highlighted by Porter et $a l^{6061}$ individuals in low-income and middle-income countries carry diverse loads, and water may not be the heaviest load carried. Because none of the studies took this into account in their analyses, the effects of manual labour in addition to water carriage may confound the apparent associations between water carriage and pain.

In a recent study, Geere $e t a t^{43}$ did not find an association between pain in the previous 7 days and history of water carriage, but did find that among people reporting pain, the area of the body in which pain was experienced was associated with a history of water carriage. Ten studies $^{1426282931-33435358}$ included some indication of the areas of the body in which water carriers experienced pain, with back and neck pain commonly reported. Geere $e t a t^{43}$ found that participants reported multiple areas of pain, and that pain areas were correlated. Principal component analysis explained $55 \%$ of the variance in pain locations and extracted two factors correlated 


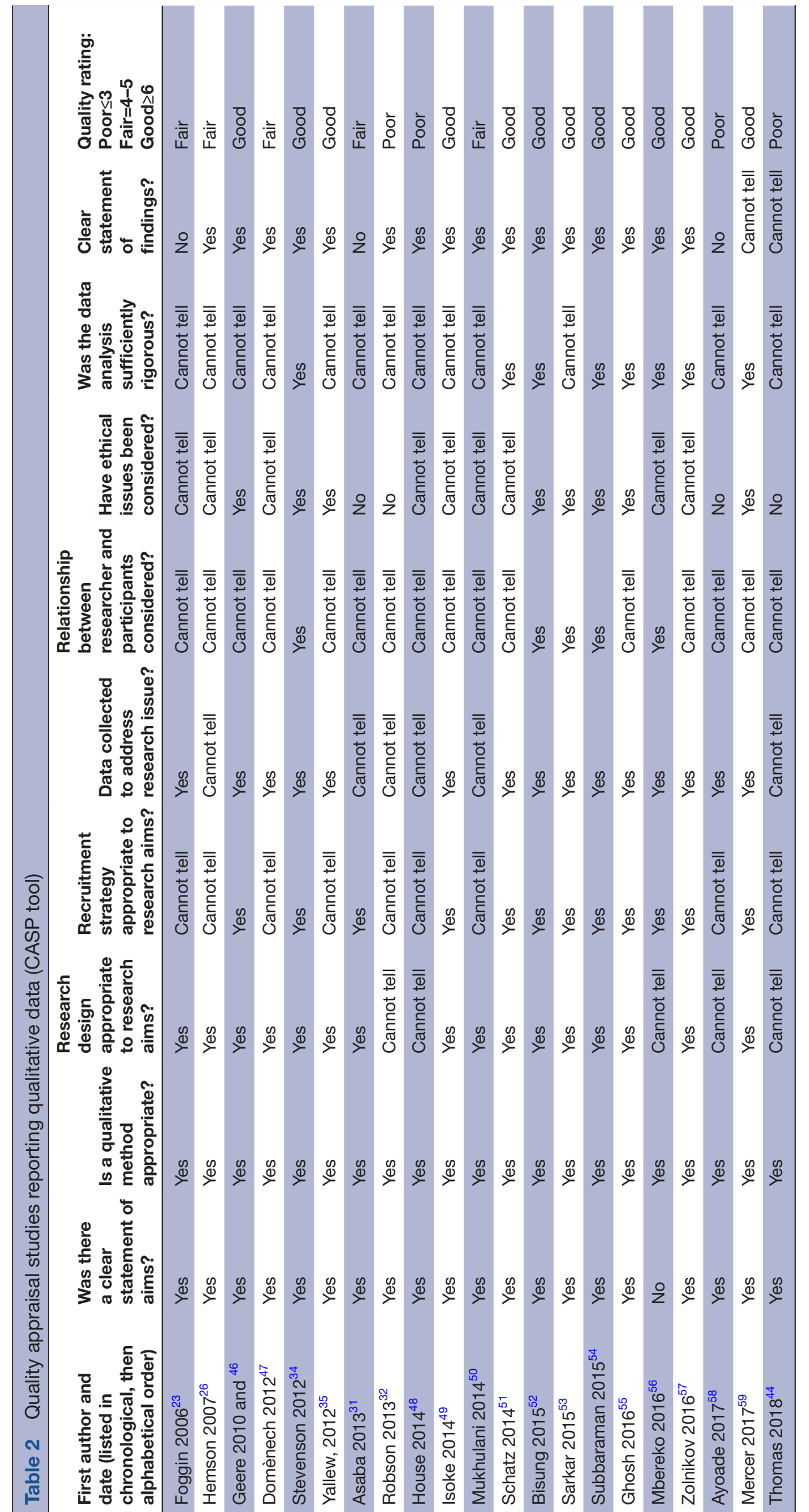


Table 3 Strength of evidence from quantitative data

\begin{tabular}{|c|c|c|c|c|}
\hline Health domain & Quality* & Quantity† & Consistency & $\begin{array}{l}\text { Strength of } \\
\text { evidence§ }\end{array}$ \\
\hline Pain and injury & One fair, eight poor & 9 & $\begin{array}{l}\text { Consistent: } \\
100 \% \text { associate WC and pain }\end{array}$ & Moderate \\
\hline $\begin{array}{l}\text { Fatigue and energy } \\
\text { expenditure }\end{array}$ & One fair, six poor & 7 & $\begin{array}{l}\text { Consistent: } \\
100 \% \text { associate WC and increased } \\
\text { fatigue }\end{array}$ & Moderate \\
\hline $\begin{array}{l}\text { Stress, mental well-being } \\
\text { or life satisfaction }\end{array}$ & $\begin{array}{l}\text { One good, one fair, } \\
\text { three poor }\end{array}$ & 5 & $\begin{array}{l}\text { Inconsistent: } \\
3(60 \%) \text { associate WC and increased } \\
\text { stress; } 2(40 \%) \text { found no significant } \\
\text { effect of reduced water collection time } \\
\text { on mental health or life satisfaction }\end{array}$ & Inconclusive \\
\hline Perinatal health & Three fair & 3 & $\begin{array}{l}\text { Consistent: } \\
100 \% \text { associate WC and reduced } \\
\text { perinatal health or care access }\end{array}$ & Moderate \\
\hline Social vulnerability & $\begin{array}{l}\text { One good, one fair, } \\
\text { five poor }\end{array}$ & 7 & $\begin{array}{l}\text { Consistent: } \\
100 \% \text { associate WC and social } \\
\text { vulnerability or risks }\end{array}$ & Moderate \\
\hline General health & One fair, three poor & 4 & $\begin{array}{l}\text { Inconsistent: } \\
3(75 \%) \text { associate WC and poorer } \\
\text { health }\end{array}$ & Inconclusive \\
\hline
\end{tabular}

${ }^{*}$ Quality score based on National Institutes of Health tool, qualitative and quantitative data of mixed methods studies rated separately, such that total number of rating scores can be greater than number of studies.

†Number of studies.

†Inconsistent: if $\leq 75 \%$ of the available studies reported the same conclusion.

§Evidence based on quality, number and the outcome of studies: strong=provided by generally consistent findings in multiple high-quality quantitative studies; moderate=generally consistent findings in one high-quality quantitative study and one low-quality study, or in multiple low-quality studies; inconclusive evidence=only one study available or inconsistent findings in multiple studies. ${ }^{20}$ WC, water carriage.

with patterns of pain distribution. The factor 'axial compression' was correlated with head, upper back, chest/rib, hands and abdomen/stomach pain. The association was proposed to indicate detrimental impacts of axial spinal loading, because participants who had previously or currently carried water had a mean increase in axial compression factor score compared with people who had never carried water, and the association was stronger among head loaders compared with those using other methods of water carriage. The factor 'soft tissue strain' was correlated with neck, upper limb pain, lower back and lower limb pain, and was slightly negatively associated with those having history of water carriage. While these findings may seem to contradict earlier data reporting complaints of neck and back pain during water carriage, the 'axial compression' pain pattern associated with water carriage was interpreted as pain referral from an underlying neck disorder.

All studies relied on self-report of pain, which is appropriate and necessary as pain is a subjective and emotional experience. ${ }^{62}$ Self-reported pain intensity scales have been shown to be valid and reliable for use in clinical trials to evaluate pain severity caused by a range of medical conditions, ${ }^{63-65}$ however, only one of the studies reported findings based on a pain intensity scale, ${ }^{33}$ and the scale was not clearly defined in the published report. No other studies qualified participants' reports of pain in terms of its quality, severity or effect on functioning. Qualification of pain is important because it is a common phenomenon, and can range from mild intensity which does not affect functioning or quality of life to severe pain which is disabling and/or reduces quality of life. Studies should focus on whether the work of water carriage is associated with pain which is of a quality or intensity sufficient to impair functioning or reduce quality of life. ${ }^{66}$

Seven studies included qualitative reports from participants, in which they associated physical injury with water fetching, ${ }^{31} 324647535859$ and four described fear of injury due to water carriage along routes or from locations frequented by dangerous animals. ${ }^{31} 323959$ One study reported three cases of a child drowning at open wells or ponds, ${ }^{31}$ participants in another study reported fear or risk of being swept away or drowning during floods ${ }^{32}$ and a further study included participants who had witnessed people struck by moving vehicles while fetching water. ${ }^{58}$

There is moderate evidence of an association between fatigue or tiredness and water carriage from quantitative data (table 3) and strong evidence from qualitative data (table 4). Five of 11 studies (12 publications) reporting tiredness, fatigue or exhaustion affecting water carriers (table 6), described associations with worsened family relationships, ${ }^{57}$ poorer health status ${ }^{24}{ }^{26}$ and reduced engagement with education. ${ }^{32} 58$ Two studies measured energy expenditure..$^{25} 28$ As an index of total energy 
Table 4 Strength of evidence from qualitative data

\begin{tabular}{|c|c|c|c|c|}
\hline Health domain & Quality* & Quantity† & Consistency & $\begin{array}{l}\text { Strength of } \\
\text { evidence }\end{array}$ \\
\hline Pain and injury & $\begin{array}{l}\text { Five good, two fair, two } \\
\text { poor }\end{array}$ & 9 & $\begin{array}{l}\text { Consistent: } \\
100 \% \text { associate WC and pain }\end{array}$ & Strong \\
\hline $\begin{array}{l}\text { Fatigue and energy } \\
\text { expenditure }\end{array}$ & $\begin{array}{l}\text { Three good, two fair, } \\
\text { two poor }\end{array}$ & 7 & $\begin{array}{l}\text { Consistent: } \\
100 \% \text { associate WC and increased } \\
\text { fatigue }\end{array}$ & Strong \\
\hline Stress & Two good, one poor & 3 & $\begin{array}{l}\text { Inconsistent: } \\
2(66 \%) \text { good quality studies associate } \\
\text { WC and increased stress, one study } \\
\text { found no effect }\end{array}$ & Strong \\
\hline Perinatal health & Two good, one poor & 3 & $\begin{array}{l}\text { Consistent: } \\
100 \% \text { associate WC and reduced } \\
\text { perinatal health or care access }\end{array}$ & Strong \\
\hline Social vulnerability & $\begin{array}{l}\text { Five good, three fair, } \\
\text { three poor }\end{array}$ & 11 & $\begin{array}{l}\text { Consistent: } \\
\text { 100\% associate WC and worse social } \\
\text { vulnerability }\end{array}$ & Strong \\
\hline General health & Two good & 2 & $\begin{array}{l}\text { Inconsistent: } \\
1(50 \%) \text { associate WC and poorer } \\
\text { health, } 1(50 \%) \text { associate WC and } \\
\text { better health }\end{array}$ & Inconclusive \\
\hline
\end{tabular}

${ }^{*}$ Quality score based on CASP tool, qualitative and quantitative data of mixed methods studies rated separately, such that total number of rating scores can be greater than number of studies.

†Number of studies.

†Inconsistent: if $\leq 75 \%$ of the available studies reported the same conclusion.

§Evidence based on quality, number and the outcome of studies: strong=provided by generally consistent findings in multiple high-quality qualitative studies; moderate=generally consistent findings in one high-quality study and one low-quality qualitative study, or in multiple lowquality studies; inconclusive evidence=only one study available or inconsistent findings in multiple studies. ${ }^{20}$

WC, water carriage.

expenditure, Rao et $a l^{25}$ described drawing water as moderate physical activity, and carrying two containers on the head as heavy physical activity, while Borah $e t a t^{8}$ categorised drawing and carrying water home as moderately to very heavy. However, the energy expenditure measurements were done on very small samples of women in India, and may not be generalisable to other populations. Together with other studies in this review, which found that rating of perceived exertion is correlated with weight of water carried and path incline, ${ }^{14}$ that energy expenditure for water carriage may be most important in food scarce regions ${ }^{47}$ and that water points which reduce water fetching increase birth rates, ${ }^{24}$ current evidence highlights that the energetic cost of water carriage has potentially detrimental effects on health and well-being, manifesting as tiredness or fatigue.

We found inconclusive evidence that water carriage is associated with stress from quantitative data (table 3) and strong evidence from qualitative data (table 4). Two rigorous qualitative studies, ${ }^{34}$ and one fair quality ${ }^{36}$ and two poor quality ${ }^{27} 34$ cross-sectional surveys, reported water carriage to be associated with stress (table 7). In these studies, psychosocial distress was identified as an effect of water carriage by thematic analysis, and measured using three different questionnaires and by quantification of hair cortisol content as a biomarker for chronic stress. Despite the different indicators of stress, all of the studies elucidated mechanisms by which water carriage might cause stress. These included feeling unsafe during water collection, ${ }^{36}$ having insufficient time for family members to spend with each other or discuss household issues ${ }^{57}$ the physical difficulty of water carriage with a young child, ${ }^{27}$ risk of physical assault or rape, extremes of temperature, queueing times and inability to complete household tasks triggering arguments between married couples. ${ }^{34}$ Considering issues related to social vulnerability which are discussed below, it is plausible that water carriers experience stress related to fear of conflict or abuse ${ }^{48}$ However, one good quality cohort study failed to find any significant association with respondents' mental well-being or life satisfaction and connection to a piped water supply, among participants with above median time spent fetching water at baseline. ${ }^{30}$ One mixed methods study failed to find an association between emotional distress and water fetching time, even though participants found water collection to be 'bothersome' because of having to collect water at night. ${ }^{44}$ The findings of these studies are inconsistent with the others, however, they should be considered with some caution. The outcome measurement of mental well-being in the study by Devoto et $a \vec{l}^{30}$ was derived from a composite score and its validity and reliability for use with the study population was not reported, and while socioeconomic status was included, other potential confounding factors which might affect 


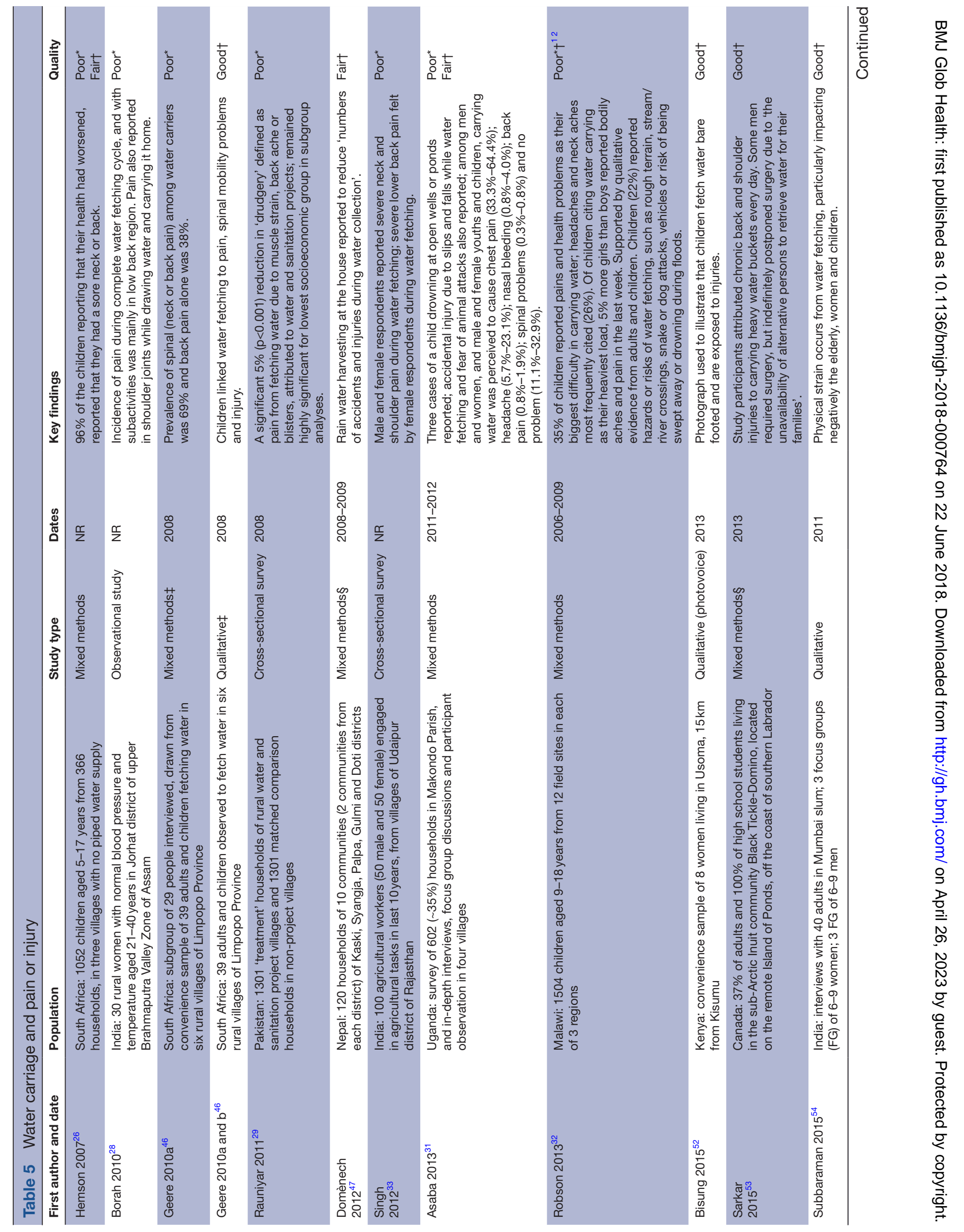




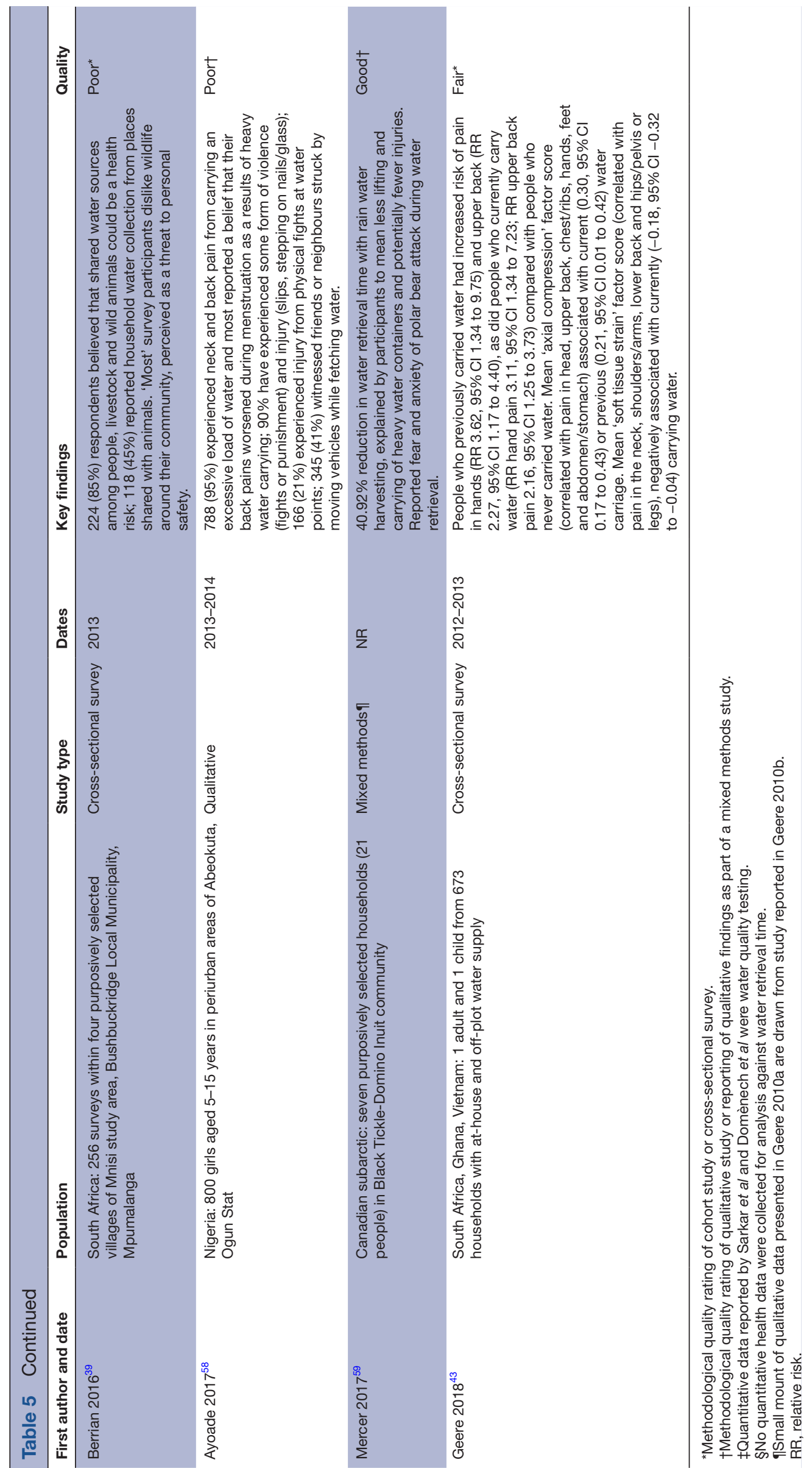




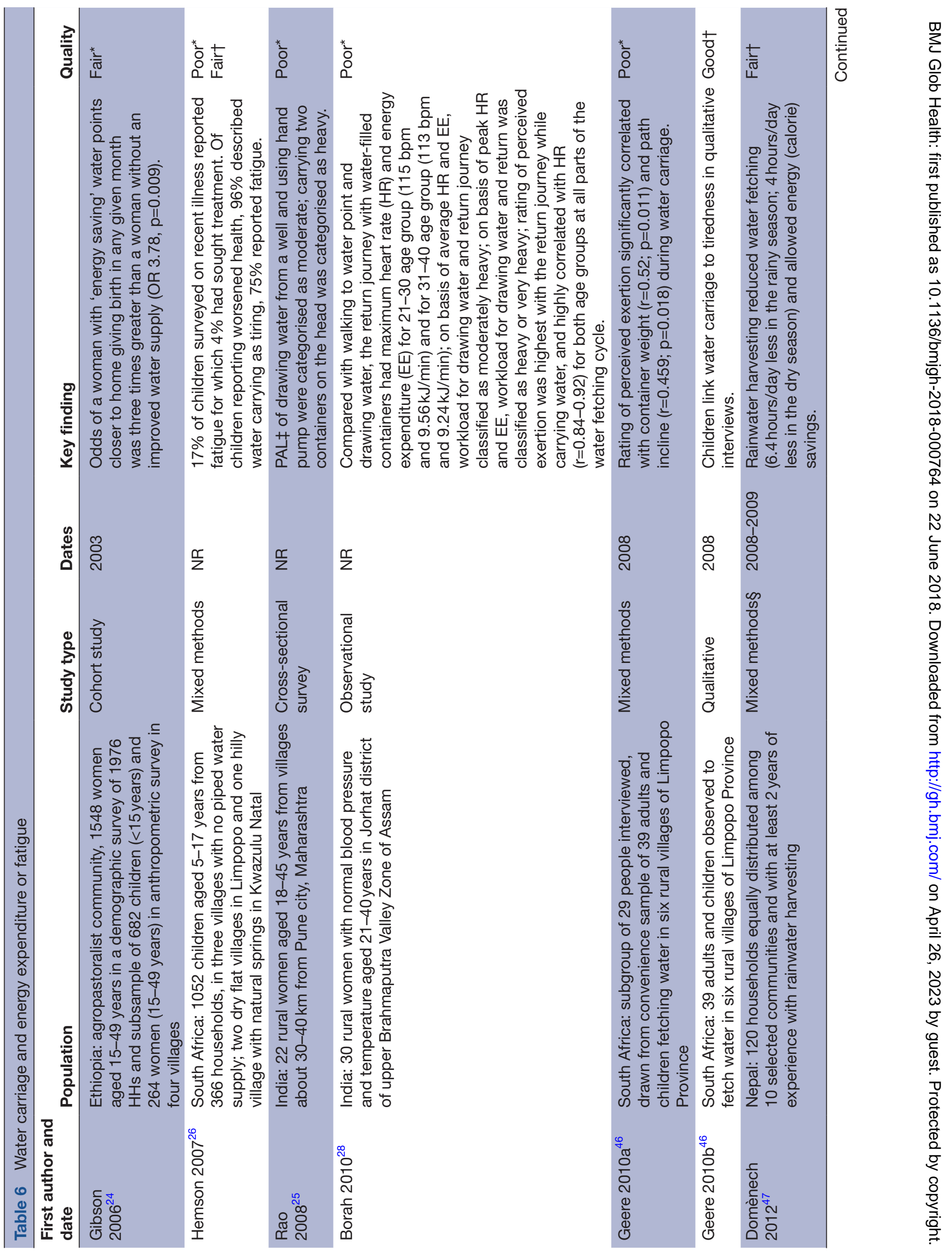




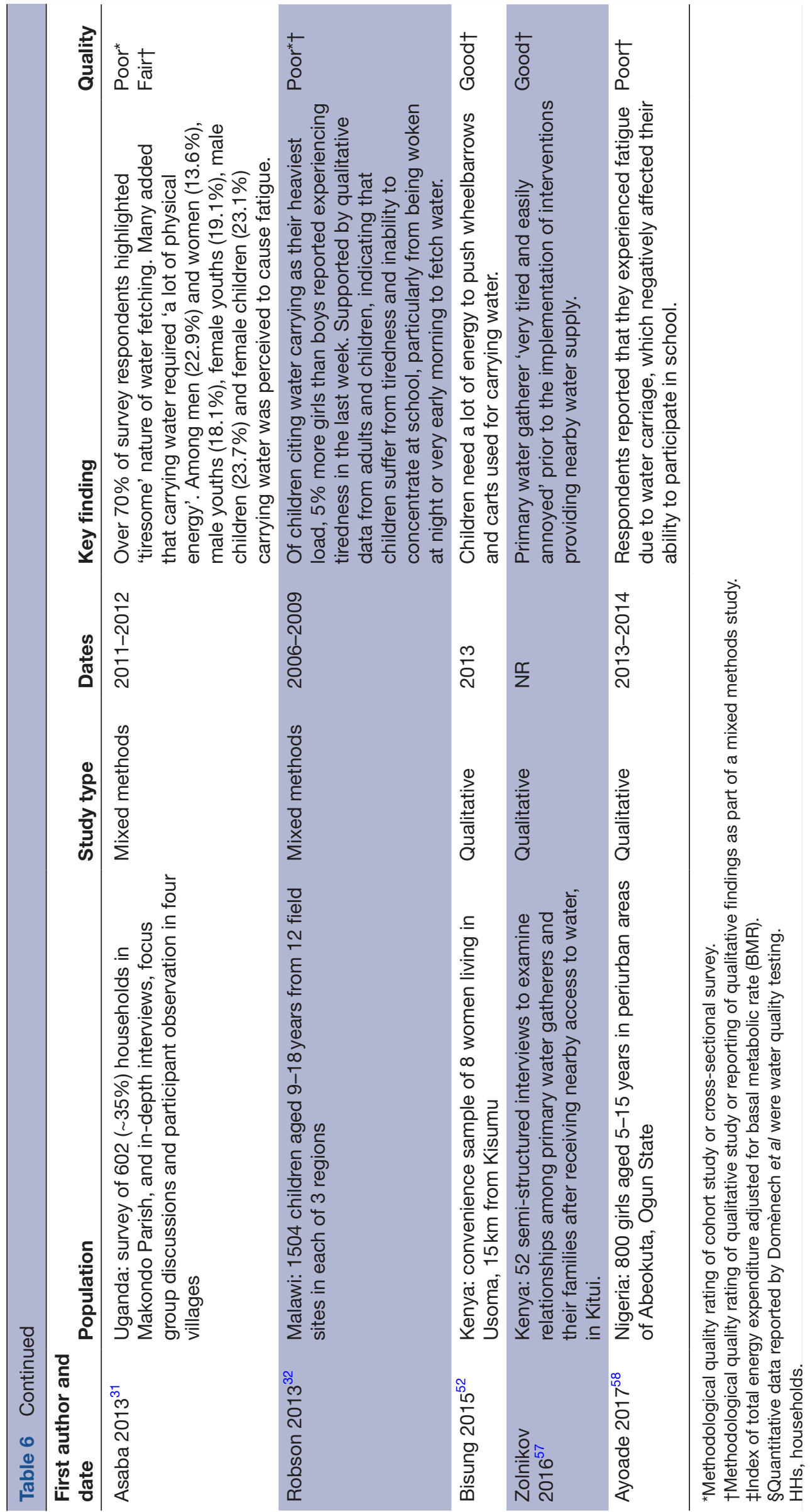




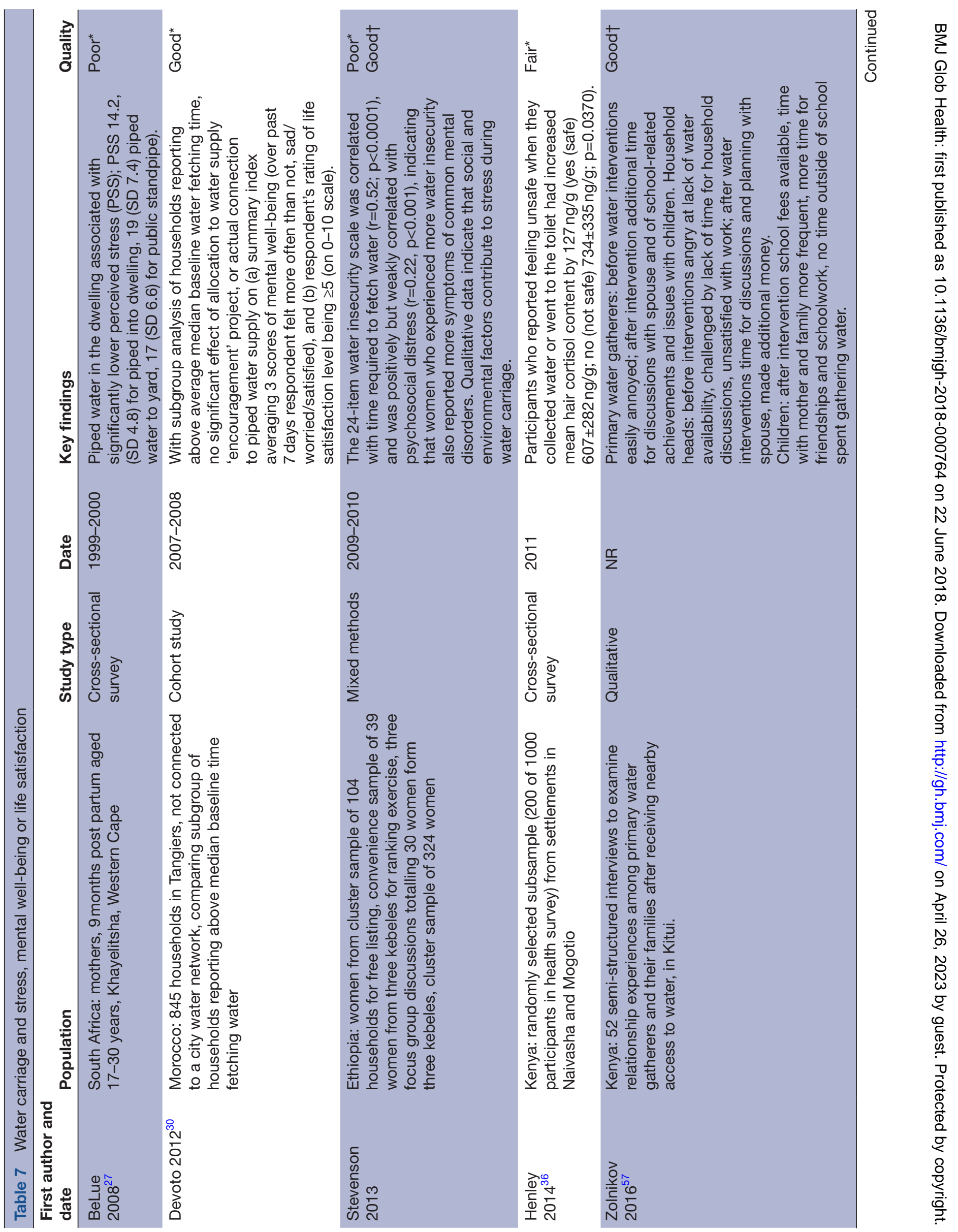




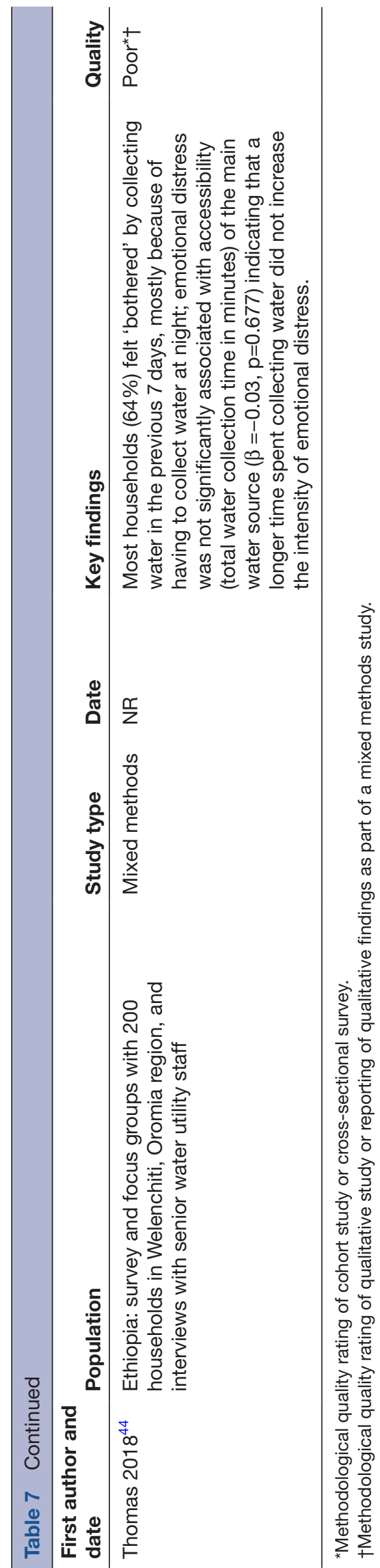

mental health and life satisfaction were not included in the analyses. The average one way time to the water source in the case study by Thomas and Godfrey ${ }^{44}$ was $<3$ min.

There is moderate quantitative evidence that perinatal health is associated with water carriage (table 3) and strong qualitative evidence (table 4). Six studies reported different aspects of perinatal health to be associated with water carriage (table 8). Two qualitative papers reported physical strain and non-specific 'health complications' from carrying $20 \mathrm{~L}$ water containers on the head during pregnancy ${ }^{52}$ and one reported mothers' views that being forced to fetch water in late pregnancy led to malnourished children. ${ }^{55}$ Quantitative studies reported reduced uptake of prenatal care services, ${ }^{22}$ six times greater odds (our calculation) of giving birth in a health facility when a husband provided help with water fetching ${ }^{38}$ and almost four times greater odds of giving birth in any given month, among women with an improved water supply closer to their home compared with those without improved water supply. ${ }^{24}$ Gibson and Mace $^{24}$ described the improved water access as an "energy saving' intervention which reduced distance to water and women's time spent water fetching. They concluded that the energy saved by the technology did not translate into an improved nutritional status for women, because it supported an increase in birth rates. While the study found a negative consequence of the increased birth rate to be increased childhood malnutrition, it nevertheless indicates a potentially detrimental impact of maternal health associated with water carriage; it suggests that prior to installation of taps the exertion of water carriage affected women's health enough to reduce birth rates, as compared with birth rates post-tap installation. While Gibson and Mace did not include nutritional interventions as possible confounding factors in their multivariable analysis, and McCray's ${ }^{22}$ outcome measure could have been affected by recall and therefore misclassification bias, the six studies provide evidence that water fetching could be significantly associated with perinatal health outcomes through behavioural and physiological mechanisms.

There is moderate quantitative evidence and strong qualitative evidence that vulnerable people are at risk of discrimination or physical, sexual and psychological abuse while they collect water (tables 3 and 4). The studies in this review provide rich qualitative evidence in good, ${ }^{4951545557}$ fair $^{314748}$ and poor quality studies ${ }^{32} 5058$ from 31 countries, and good, ${ }^{30}$ fair $^{31} 37$ or poor ${ }^{31} 32354142$ quantitative evidence from 6 countries (table 9). People may be vulnerable because of age, gender, disability, health status or ethnicity.

There is inconclusive evidence of a relationship between water carriage and self-rating of general health, because of inconsistent findings in the five studies (tables 3 and 4). There is an indication of a dose-response relationship between water carriage and selfrating of health in three ${ }^{212326}$ of the five studies reporting 


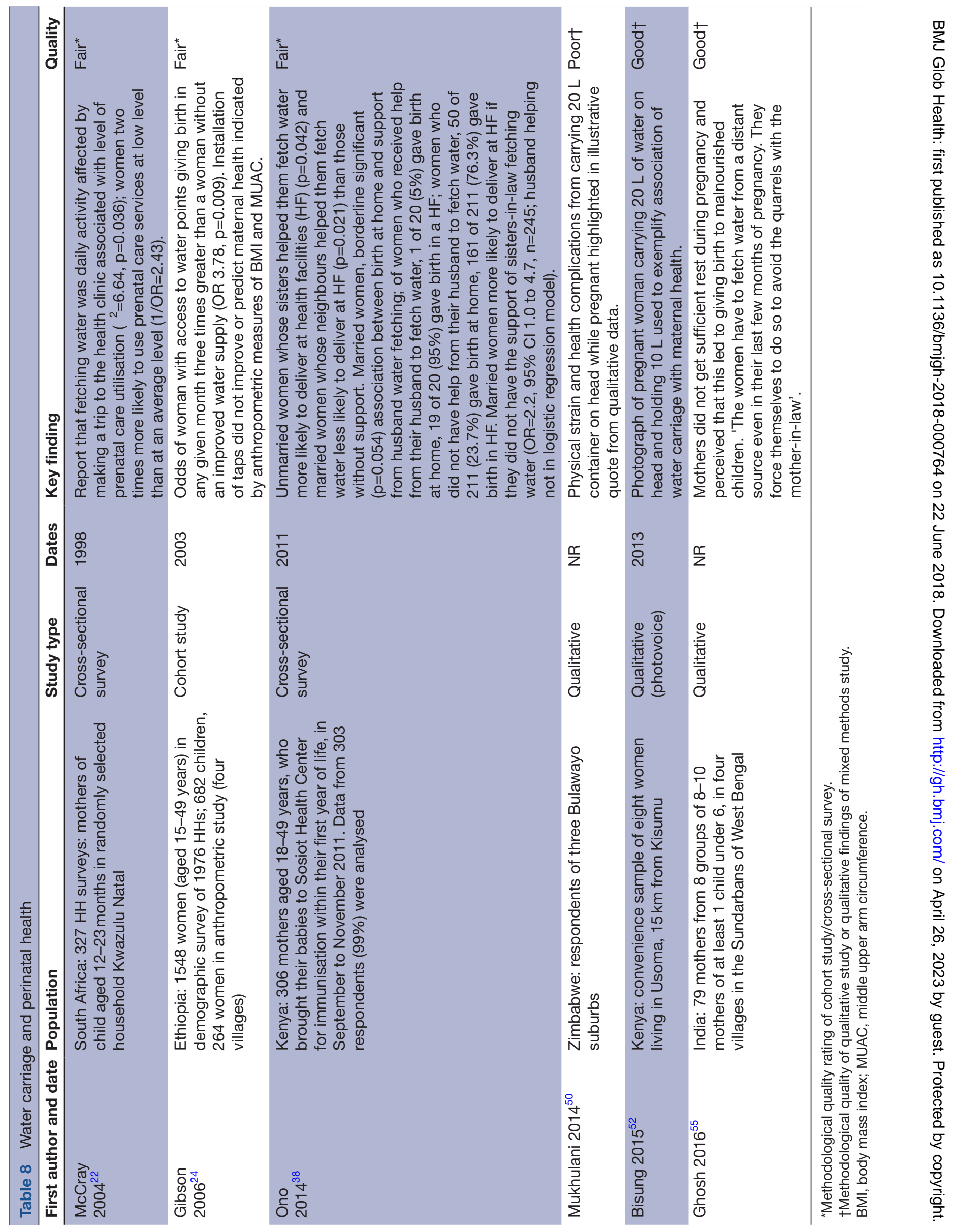




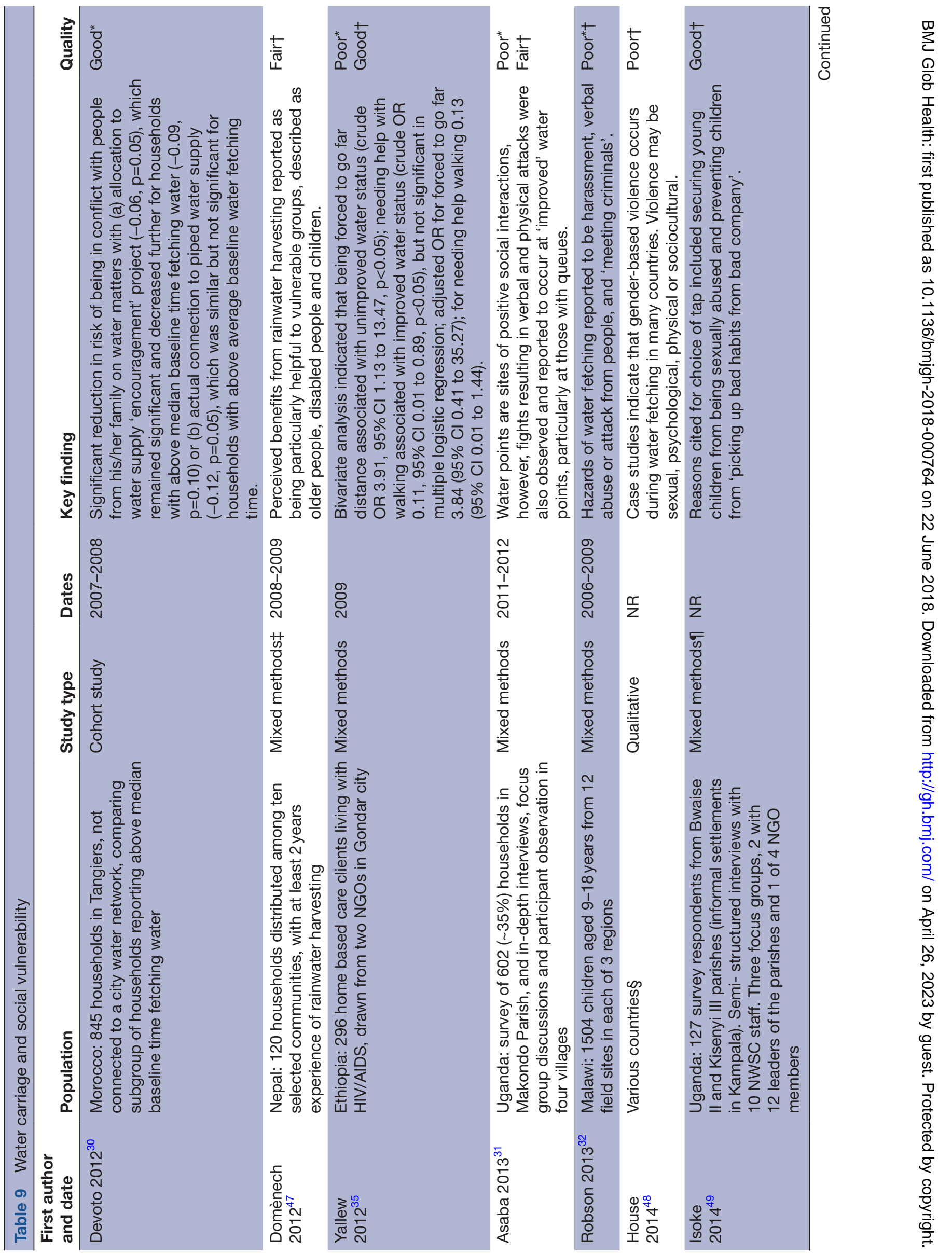




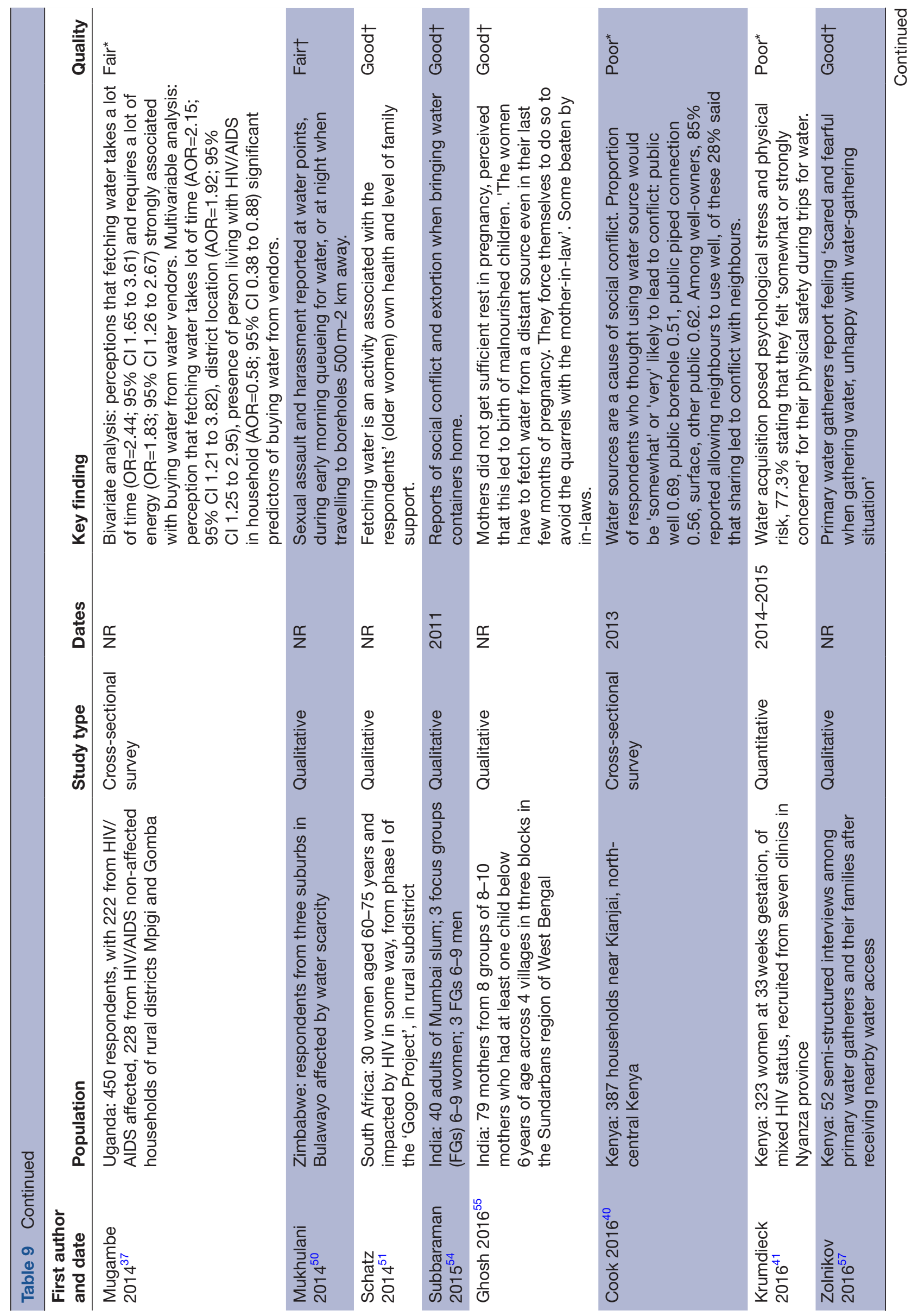

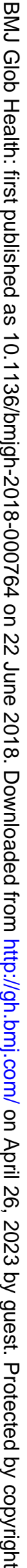


general health of water carriers, with greater amounts of time spent water fetching linked with poorer health for both children and adults (table 10). These findings were inconsistent with those of Geere $e t a l,{ }^{43}$ who found that adults who currently or previously carried water, had a better (lower=healthier) mean general health rating score than adults who never carried water, while children who currently carried water reported better, and children who previously carried water reported worse health, compared with children who had never carried water. In qualitative data from an earlier pilot study, Geere et $a t^{46}$ found that some children linked water carriage to better health and stronger resilience to diseases such as 'influenza', others to meeting basic needs and some to experiencing unfair workloads.

The inconsistencies may be due to different methods used for participants to rate their general health, and differences in confounding factors incorporated into the analyses. In the three of four studies which attempted to scale or categorise health status, ${ }^{2123}{ }^{26}$ recall of occasions of illness or comparison of current to previous health status was required of respondents. This may introduce bias or error to the classification of health status, weakening internal validity of the studies and rendering the findings inaccurate. ${ }^{17}$ Self-rated health 'today' on a simple 5-point scale has been found to have high test-retest reliability and to be an excellent predictor of future health in some studies, however, reliability of self-rated health status has also been shown to be affected by age, income and occupation in some populations. ${ }^{67}$ Hemson's ${ }^{26}$ findings may therefore have been influenced by recall and confounding factors, because the statistics presented are descriptive and lack analysis of the effect of variables such as age, gender and socioeconomic status. These variables were considered in the regression analyses reported by Bour, ${ }^{21}$ Foggin $e t a l^{23}$ and Geere $e t a l,{ }^{43}$ with Foggin $e t a l$ reporting a very strong association between increased time spent water fetching and poorer general health. However, other potential confounding factors which were not included in analyses, such as hygiene practices, access to healthcare or sanitation coverage, could have influenced the results in all studies. No studies used a longitudinal cohort design to determine a temporal relationship between water fetching and health status, and all could have been affected by confounding factors which were not included in analyses.

\section{DISCUSSION}

This is the first systematic review of the association of the work of water carriage with the health of water carriers. Forty-two studies were included in the review. Direct detrimental health impacts were mainly reported, such as increased pain, fatigue and stress. Indirect detrimental health impacts were also reported and were related to perinatal health and social vulnerability. These included serious health issues such as physical abuse and rape. The ability of the studies reporting quantitative data to 


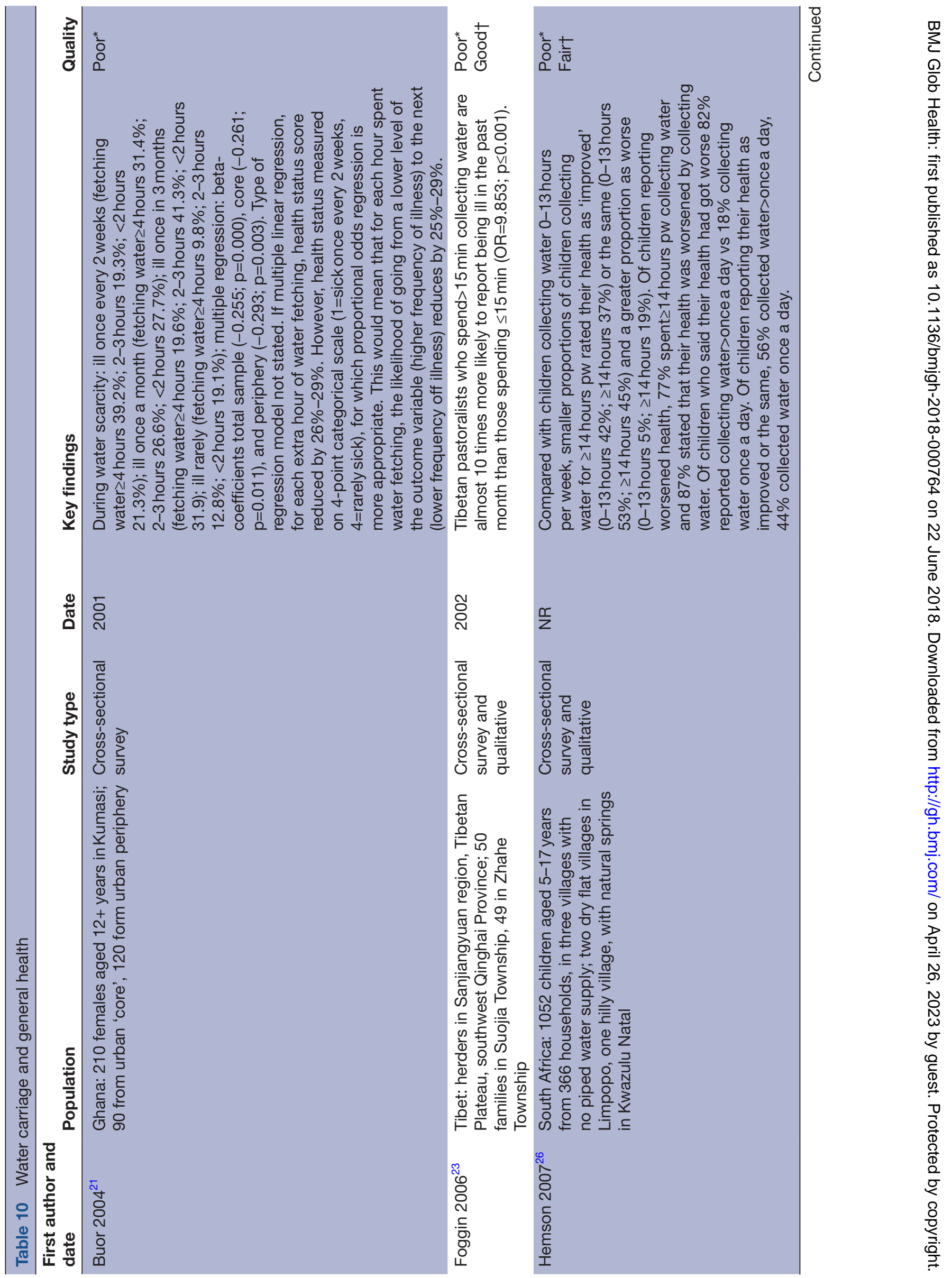




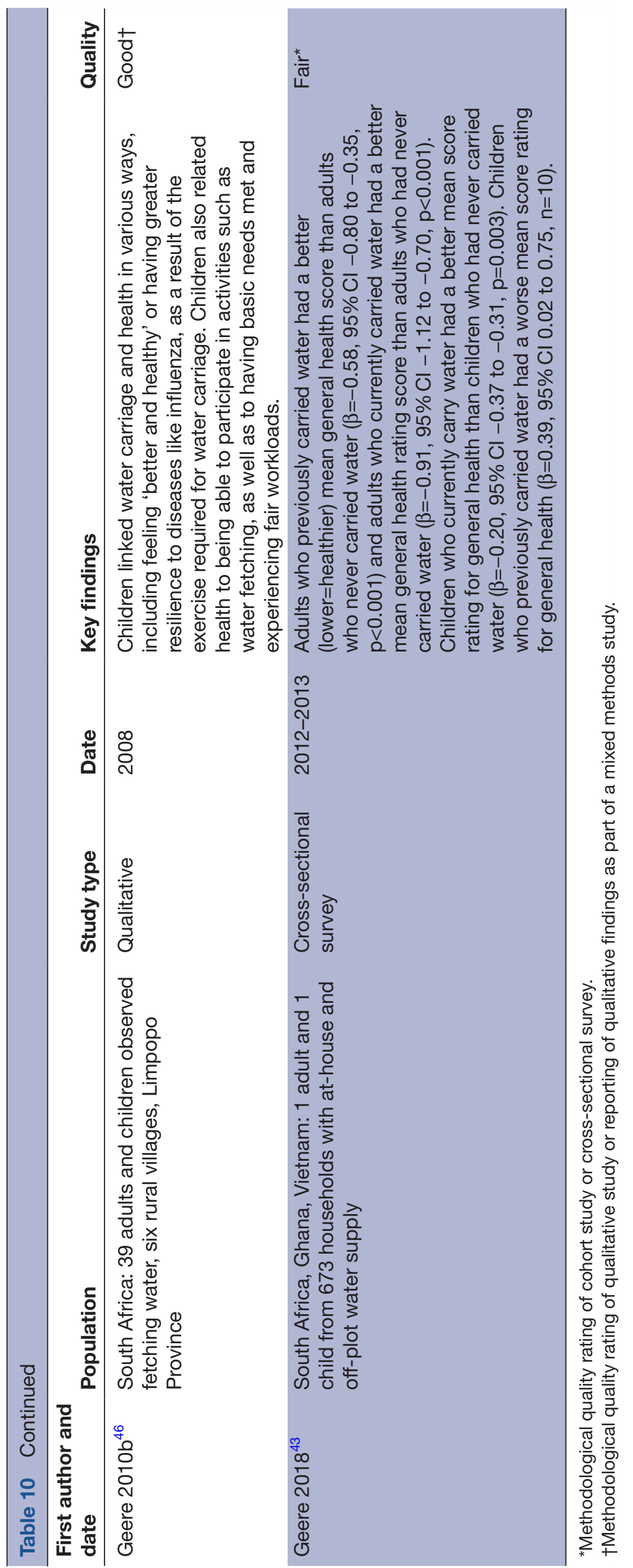


demonstrate a cause and effect relationship is limited because of study design and fair or poor methodological quality. The only cohort study in the review rated as $\operatorname{good}^{30}$ was of limited value, as in the main analyses of the health effects of 'encouragement' and actual household connection to piped water supply, people carrying water by container were not disaggregated from those connected by hose to a public tap or neighbour, the health outcome measures reported for relevant subgroup analyses were limited and confounding factors did not include other forms of manual labour. A greater number of studies reporting qualitative data were rated as having good methodological quality, and while these provide insight into the lived experience of fetching water, they cannot provide strong evidence of a causal relationship, as the actual experience of pain or other health effects may be mediated by confounding factors and bias. Overall, the evidence in this review indicates that the work of water carriage is more often associated with harm rather than benefit to the water carriers' health. Our findings indicate that the health outcomes associated with water carriage create barriers to achieving the targets of many of the SDGs.

Qualitative studies clearly indicate that water carriers experience pain and feel exposed to risk of injury during water carriage, which is commonly performed by carrying containers on the head. The findings are supported by Lloyd $e t a l,{ }^{68}$ who reported that discomfort in the neck was, in all cases, the cause of early termination of headloading trials during a laboratory experiment. Geere $e t a t^{43}$ proposed that the pain pattern they observed to be associated with water carriage might indicate referred pain as a consequence of tissue deformation under compressive loading, or long-term structural changes such as cervical spondylosis. Evidence of advanced cervical spondylosis has been reported among porters and people who apply loads to the head (head loading), ${ }^{69-71}$ suggesting that this common method of water carriage may be sufficient to cause structural changes in bone and the soft tissues of the spine. Such changes have been proposed in experimental studies to occur as a consequence of biomechanical stress and strain. ${ }^{72}$ Particularly in the cervical spine, spondylosis may lead to neurological impairment, such as radiculopathy or myelopathy, and related disability. ${ }^{734}$ However, none of the studies reporting pain or injury affecting water carriers were longitudinal cohort studies. Hence, it remains unknown whether the loading patterns typical of domestic water carriage, by head loading or other methods, are sufficient to have important long-term effects on the musculoskeletal system and to increase risk of neurological compromise. This question is particularly important for populations in sub-Saharan Africa, where other risk factors for myelopathy, including nutritional or infectious diseases such as HIV, tuberculosis or schistosomiasis, are also common ${ }^{75-77}$ and may increase susceptibility to adverse impacts of head loading. It is also important to recognise that many people will carry diverse loads in addition to water, ${ }^{60}$ and future studies should include detail of other head loading and manual labour as potential factors confounding the effects of water carriage.

No studies attempted to conduct any detailed clinical assessment of their study participants, ${ }^{78}$ or reported excluding participants with long-term health conditions which might cause pain and modify an association between symptoms and water carriage. This may be due to the practical and ethical challenges of conducting clinical assessments in areas of limited health services coverage, the likely situation in many areas where water carriage studies would typically be conducted. ${ }^{6}$ However, future studies would be strengthened by incorporating some aspects of clinical assessment to supplement self-reported health outcomes. For example, a medical history could be combined with evaluation of whether movement, compression stress or palpation of pain sensitive structures provokes symptoms comparable to those experienced during water carriage ${ }^{79}$ This would help to identify a likely cause of symptoms and could confirm whether mechanical loading during water carriage is a plausible mechanism of pain production in study participants.

This review has found moderate quantitative and strong qualitative evidence that tiredness or fatigue is associated with water carriage. Head loading by African women has been described as an energy efficient way of carrying loads. ${ }^{80}{ }^{81}$ However, one study tested the 'free ride' hypothesis for head loads compared with back loads, and found that it was not generalisable, with significant individual differences in energetic cost. ${ }^{82}$ In larger households, or those caring for young children, aged parents or people living with disability or long-term conditions, their need for water may be high and water carriage may become a demanding daily chore, particularly if it falls on one woman or her children. Differences in the capacity of individuals to meet their household's need for water will influence water security and could exacerbate interhousehold and intercommunity inequalities of water access, a direct challenge to SDG 6 target 6.1 'universal and equitable access to safe and affordable drinking water for all' .

We found inconclusive quantitative and strong qualitative evidence that stress is associated with water carriage. Qualitative evidence highlighted that the experience of stress associated with water carriage could be due to reduced family time and poorer interpersonal relationships, conflicts which arise in the community or at home over water use and domestic tasks, the physical challenges of collecting water and lack of safety. Water fetching is also indirectly linked to stress, by increasing water insecurity, and feelings of worry or shame from inability to keep oneself or one's children clean, or complete expected household chores such as laundry, cleaning and cooking. The one good quality cohort study in this review did not find a significant effect of connection to a piped water supply on respondents' mental health or life satisfaction, however, their mental health index was derived from the average of three separate measures of well-being, and its 
reliability and validity for use in the study population is not clear. While socioeconomic confounding factors were included in the analyses, other factors which may have also affected mental health and well-being in the population studied, were not included in the analysis. Overall, our findings are similar to a review of water insecurity and psychosocial stress, ${ }^{83}$ and highlight that reducing the work of water carriage has potential to benefit women's and children's mental health in settings where water carriage is physically challenging, unsafe or exacerbates water insecurity. This aligns with SDG target 3.4 to 'promote mental health and well-being' ${ }^{6}$ and further good quality cohort or intervention studies, using valid and reliable outcome measures of stress, mental health and well-being are warranted.

The moderate quantitative and strong qualitative evidence that water carriage can affect perinatal health and reduce uptake of health services is particularly relevant to SDG 3 targets 1 and 2, to reduce maternal and new born deaths, and 7, ensure access to reproductive healthcare services. Fetching water also sets the scene in which health risks due to social vulnerability are realised. Vulnerable people include women, children, displaced people, people with disability and people living with HIV AIDS. It is likely that cases of abuse are under-reported, due to shame and fear of further discrimination or reprisals against the victim or their family, and ineffective or inappropriate policing and support services. ${ }^{48}$ Older adults are also vulnerable, as they may not be capable of collecting enough water from off-plot sources because of age-related health problems, and may lack support from younger family members for fetching water. ${ }^{84}{ }^{85}$ Future studies should investigate how to reduce social vulnerability and ensure safe access to safe water, and are needed to strengthen the existing evidence base and identify ways to meet the 'universal' aspect of SDG 6 , target 6.1.

Study findings differ on the association between general health and water carriage. Apart from differences in study design, the perceived and reported general health impact of water carriage may also be mediated by whether the work is perceived as 'normal', whether it allows basic needs to be met and by how well the workload matches the water carrier's physical capacity for work and the comparative workload of other people. ${ }^{46}$ In the study which reported a rating of health 'today', ${ }^{43}$ the association of better health with current or past water carriage might indicate a selection process, whereby healthier people are allocated the task of fetching water. It may also indicate a beneficial health effect of regular physical activity undertaken since adolescence. ${ }^{86}$ Overall, the findings on general health from studies in this review are inconsistent and therefore provide inconclusive evidence. However, in light of this review's findings in relation to other domains of health, further research with longitudinal cohort studies is warranted.

Our review has used a sensitive search strategy to identify published reports in academic and grey literature. While one good quality cohort study evaluating the impact of connection to piped water supply was found, its findings were of limited value for the review. A limitation of our review is that we did not contact study authors for additional information or data. All other studies were either qualitative or used cross-sectional surveys, and we therefore cannot make causal inferences. However, the qualitative studies included in this review provide insight into people's experiences of water fetching and the mechanisms by which it might affect their health, and together with the substantial number of cross-sectional studies reporting that water carriage is negatively associated with health outcomes, indicate that further good quality research is warranted.

The design of future studies should ideally evaluate the temporal relationship between water carriage (exposure) and health (outcome) to evaluate cause and effect, or use randomisation and control groups or villages to reduce risk of confounding and bias. They should also include multivariable analyses of important potential confounding factors, such as socioeconomic level, health status and comorbidities, manual labour and carriage of loads other than water. ${ }^{87}$ Studies should incorporate standardised, valid and reliable methods of exposure and outcome measurement, including measured time spent carrying water, weight of water carried, frequency of water carriage, years of exposure and methods of water carriage. Health outcome measures should be piloted for reliability and validity of use in the study populations, and include severity, duration, location and functional impact of pain, as well as indicators of fatigue, stress, mental health and general health, social vulnerability and perinatal healthcare access. Clinical assessment by trained health workers could supplement self-reported outcome measures to support better evaluation of the health status of study participants against selection criteria, at baseline assessment and follow-up. While the challenges of limiting the effects of confounding and bias in WASH research are well recognised, ${ }^{88}$ a stronger body of evidence derived from good quality studies with comparable health outcome measures will allow future reviews to better evaluate risk of bias, more precisely estimate measures of treatment or intervention effect and conduct sensitivity analyses to reduce risk of overall bias.

Through its association with pain, fatigue, stress and reduced access to perinatal healthcare services, the existing evidence suggests that water carriage is a potentially important barrier to achievement of many health targets set for SDG 3. Because in most households of low-income and middle-income countries, it is women and girls who fetch water for household use, it will also compromise SDGs related to gender equality, quality education for all and reducing inequalities. Because water is essential for life, but fetching it is often not safe, water carriage is also a barrier to ensuring safe and inclusive societies, and decent work for all, a further challenge to reducing poverty in all its forms. However, it is important to recognise that water may be carried in addition to other loads, and it may not be the heaviest or key 
porterage task leading to health issues. Combined, all of these factors reduce the likelihood of achieving SDG 6 target 1 by 2030: 'universal and equitable access to safe and affordable drinking water for all'.

\begin{abstract}
Acknowledgements Hazel Marsh provided translation of articles published in Spanish, Paul Hunter of articles published in French, Moa Cortobius of articles published in Swedish, Eneida Moshi of articles in Portugese and Umut Yukaruc of articles in Turkish. Jack Morris assisted with data extraction during scoping searches conducted in preparation for this review.
\end{abstract}

Contributors J-ALG conceived of the review, completed the electronic data base searches, selected papers to include in the review against selection criteria, extracted data, appraised articles reporting qualitative and quantitative data, wrote the first draft of the paper, reviewed subsequent drafts and reviewed and approved the final draft; MC conceived of the review, contacted experts in the field of water and health, provided translation of Swedish papers, reviewed drafts and reviewed and approved the final draft of the paper; JHG appraised articles reporting quantitative data, reviewed drafts and reviewed and approved the final draft of the paper; $\mathrm{CCH}$ appraised articles reporting qualitative data, reviewed drafts and reviewed and approved the final draft of the paper; PRH selected papers to include in the review against selection criteria, provided translation of French papers, appraised articles requiring consensus on quality rating, reviewed drafts and reviewed and approved the final draft of the paper.

Funding This review was supported, but not funded, by the International Labour Organisation. The work was also supported, and preliminary data extraction during scoping searches funded in part by Stockholm International Water Institute.

Competing interests None declared.

Patient consent Not required.

Provenance and peer review Not commissioned; externally peer reviewed.

Open access This is an open access article distributed in accordance with the Creative Commons Attribution Non Commercial (CC BY-NC 4.0) license, which permits others to distribute, remix, adapt, build upon this work non-commercially, and license their derivative works on different terms, provided the original work is properly cited and the use is non-commercial. See: http://creativecommons.org/ licenses/by-nc/4.0/

(c) Article author(s) (or their employer(s) unless otherwise stated in the text of the article) 2018. All rights reserved. No commercial use is permitted unless otherwise expressly granted.

\section{REFERENCES}

1. WHO. Constitution of WHO: principles. Geneva: World Health Organisation, 2018. (accessed 01 May 2018).

2. WHO. Statement by Dr Margaret Chan, WHO Director-General, on the occasion of World Water Day, 22 March 2007. Geneva: World Health Organisation, 2007. (accessed 26 Nov 2007).

3. WHO, UNICEF. Safely managed drinking water - thematic report on drinking water. Geneva: World Health Organisation (WHO) and the United Nations Children's Fund (UNICEF), 2017.

4. ICLS. ILOResolution concerning statistics of work, employment and labour underutilization. In: , ed. Geneva: Nineteenth International Conference of Labour Statisticians, 2013.

5. United Nations. Goal 6: Ensure access to water and sanitation for all Geneva: UN Web Services Section, Department of Public Information. United Nations, 2015;2015.

6. United Nations. Goal 3: Ensure healthy lives and promote well-being for all at all ages Geneva: UN Web Services Section, Department of Public Information. United Nations, 2015;2015.

7. UN. UNTransforming our world: the 2030 agenda for sustainable development. In: , ed. 2015:41

8. Wang X, Hunter PR. A systematic review and meta-analysis of the association between self-reported diarrheal disease and distance from home to water source. Am J Trop Med Hyg 2010;83:582-4.

9. Pickering AJ, Davis J. Freshwater availability and water fetching distance affect child health in sub-Saharan Africa. Environ Sci Technol 2012;46:2391-7.

10. Hunter PR, MacDonald AM, Carter RC. Water supply and health PLoS Med 2010;7:e1000361.

11. Stelmach RD, Clasen T. Household water quantity and health: a systematic review. Int J Environ Res Public Health 2015;12:5954-74.
12. Geere JA, Cortobius M. Who carries the weight of water? Fetching water in rural and urban areas and the implications for water security. Water Alternatives 2017;10:513-40.

13. Graham JP, Hirai M, Kim SS. An Analysis of Water Collection Labo among Women and Children in 24 Sub-Saharan African Countries. PLoS One 2016;11:e0155981.

14. Geere JA, Hunter PR, Jagals P. Domestic water carrying and its implications for health: a review and mixed methods pilot study in Limpopo Province, South Africa. Environ Health 2010;9:52.

15. Geere J. Health impacts of water carriage. In: Bartram J, Baum R, Coclanis PA, eds. Routledge Handbook of Water and Health. London and New York: Routledge, 2015

16. Evans B, Bartram J, Hunter PR, et al. Public Health and Social Benefits of at-house Water Supplies Final Report. UK: University of Leeds, 2013.

17. NIH. Quality Assessment Tool for Observational Cohort and CrossSectional Studies USA: department of health and human services. 2017. https://www.nhlbi.nih.gov/health-pro/guidelines/in-develop/ cardiovascular-risk-reduction/tools/cohort (accessed 03 Aug 2017)

18. CASP. 10 questions to help you make sense of qualitative research 2017. 2017. http://docs.wixstatic.com/ugd/dded87_25658615020e 427da194a325e7773d42.pdf (accessed 03 Aug 2017).

19. West S, King V, Carey TS, et al. Systems to rate the strength of scientific evidence. Evidence Report/Technology Assessment No 47 Rockville, MD: Agency for Healthcare Research and Quality, 2002.

20. Hoogendoorn WE, van Poppel MN, Bongers PM, et al. Physical load during work and leisure time as risk factors for back pain. Scand $J$ Work Environ Health 1999;25:387-403.

21. Buor D. Water needs and women's health in the Kumas metropolitan area, Ghana. Health Place 2004;10:85-103.

22. McCray TM. An issue of culture: the effects of daily activities on prenatal care utilization patterns in rural South Africa. Soc Sci Med 2004;59:1843-55.

23. Foggin PM, Torrance ME, Dorje D, et al. Assessment of the health status and risk factors of Kham Tibetan pastoralists in the alpine grasslands of the Tibetan plateau. Soc Sci Med 2006;63:2512-32.

24. Gibson MA, Mace R. An energy-saving development initiative increases birth rate and childhood malnutrition in rural Ethiopia. PLoS Med 2006:3:e87.

25. Rao S, Gokhale M, Kanade A. Energy costs of daily activities for women in rural India. Public Health Nutr 2008;11:142-50.

26. Hemson D. 'The toughest of chores': policy and practice in children collecting water in South Africa. Policy Futures in Education 2007;5:315-26.

27. BeLue R, Schreiner AS, Taylor-Richardson K, et al. What matters most: an investigation of predictors of perceived stress among young mothers in Khayelitsha. Health Care Women Int 2008;29:638-48.

28. Borah R, Kalita M, Bhuyan B. Physiological workload of fetching water. Asian Journal of Home Science 2010;4:305-8.

29. Rauniyar G, Orbeta A, Sugiyarto G. Impact of water supply and sanitation assistance on human welfare in rural Pakistan. $J$ Dev Effect 2011;3:62-102.

30. Devoto F, Duflo E, Dupas P, et al. Happiness on tap: piped water adoption in Urban Morocco. Am Econ J Econ Policy 2012;4:68-99.

31. Asaba RB, Fagan GH, Kabonesa C, et al. Beyond distance and time: gender and the burden of water collection in rural Uganda. The Journal of Gender and Water 2013;2:31-8.

32. Robson E, Porter G, Hampshire K, et al. Heavy loads: children's burdens of water carrying in Malawi. Waterlines 2013;32:23-35.

33. Singh S, Sinwal N, Rathore H. Gender involvement in manual material handling ( $\mathrm{mmh}$ ) tasks in agriculture and technology intervention to mitigate the resulting musculoskeletal disorders. Work 2012;41 Suppl 1:4333-41.

34. Stevenson EG, Greene LE, Maes KC, et al. Water insecurity in 3 dimensions: an anthropological perspective on water and women's psychosocial distress in Ethiopia. Soc Sci Med 2012;75:392-400.

35. Yallew WW, Terefe MW, Herchline TE, et al. Assessment of water, sanitation, and hygiene practice and associated factors among people living with HIV/AIDS home based care services in Gondar city, Ethiopia. BMC Public Health 2012;12:1057.

36. Henley P, Lowthers M, Koren G, et al. Cultural and socio-economic conditions as factors contributing to chronic stress in sub-Saharan African communities. Can J Physiol Pharmacol 2014;92:725-32.

37. Mugambe RK, Larkan F, Ssempebwa JC, et al. Access to and perceptions towards water, sanitation and hygiene: a case of HIV/ AIDS affected and non-affected households in rural Uganda. $J$ Public Health 2014;22:287-96.

38. Ono M, Matsuyama A, Karama M, et al. Association between socia support and place of delivery: a cross-sectional study in Kericho, Western Kenya. BMC Pregnancy Childbirth 2013;13:214. 
39. Berrian AM, van Rooyen J, Martínez-López B, et al. One Health profile of a community at the wildlife-domestic animal interface, Mpumalanga, South Africa. Prev Vet Med 2016;130:119-28.

40. Cook J, Kimuyu P, Whittington D. The costs of coping with poor water supply in rural Kenya. Water Resour Res 2016;52:841-59.

41. Krumdieck NR, Collins SM, Wekesa P, et al. Household water insecurity is associated with a range of negative consequences among pregnant Kenyan women of mixed HIV status. J Water Health 2016;14:1028-31.

42. Dapaah EK, Harris LM. Framing community entitlements to water in Accra, Ghana: a complex reality. Geoforum 2017;82:26-39.

43. Geere JA, Bartram J, Bates L, et al. Carrying water may be a major contributor to disability from musculoskeletal disorders in low income countries: a cross-sectional survey in South Africa, Ghana and Vietnam. J Glob Health 2018;8:010406.

44. Thomas V, Godfrey S. Understanding water-related emotional distress for improving water services: a case study from an Ethiopian small town. J Water Sanit Hyg Dev 2018;8:196-207.

45. Hennegan J, Dolan C, Wu M, et al. Schoolgirls' experience and appraisal of menstrual absorbents in rural Uganda: a cross-sectional evaluation of reusable sanitary pads. Reprod Health 2016;13:143.

46. Geere JL, Mokoena MM, Jagals P, et al. How do children perceive health to be affected by domestic water carrying? Qualitative findings from a mixed methods study in rural South Africa. Child Care Health Dev 2010;36:818-26.

47. Domènech L, Heijnen H, Saurí D. Rainwater harvesting for human consumption and livelihood improvement in rural Nepal: benefits and risks. Water and Environment Journal 2012;26:465-72.

48. House S, Ferron S, Sommer M, et al. Violence, Gender \& WASH: A Practitioner's Toolkit - Making water, sanitation and hygiene safer through improved programming and services. London, U.K: WaterAid/SHARE, 2014

49. Isoke J, Van Dijk MP. Factors influencing selection of drinking water technologies for urban informal settlements in Kampala. Water and Environment Journal 2014;28:423-33.

50. Mukuhlani T, Nyamupingidza MT. Water scarcity in communities, coping strategies and mitigation measures: the case of Bulawayo. $J$ Sustain Dev 2014;7:144-60.

51. Schatz E, Gilbert L. "My Legs Affect Me a Lot... I Can No Longer Walk to the Forest to Fetch Firewood": challenges related to health and the performance of daily tasks for older women in a high HIV context. Health Care Women Int 2014;35:771-88.

52. Bisung E, Elliott SJ, Abudho B, et al. Dreaming of toilets: using photovoice to explore knowledge, attitudes and practices around water-health linkages in rural Kenya. Health Place 2015;31:208-15.

53. Sarkar A, Hanrahan M, Hudson A. Water insecurity in Canadian indigenous communities: some inconvenient truths. Rural Remote Health 2015;15:3354

54. Subbaraman R, Nolan L, Sawant K, et al. Multidimensional measurement of household water poverty in a Mumbai Slum: looking beyond water quality. PLoS One 2015;10:e0133241.

55. Ghosh U, Bose S, Bramhachari R, et al. Expressing collective voices on children's health: photovoice exploration with mothers of young children from the Indian Sundarbans. BMC Health Serv Res 2016;16(Suppl 7):625.

56. Mbereko A, Scott $D$, John Chimbari $M$. The relationship between HIV and AIDS and water scarcity in Nyamakate resettlements land, north-central Zimbabwe. Afr J AIDS Res 2016;15:349-57.

57. Zolnikov TR, Blodgett Salafia E. Improved relationships in eastern Kenya from water interventions and access to water. Health Psychol 2016;35:273-80.

58. Ayoade A, Sikiru S, Okanlawon PO. Assessment of water provision and associated risks among children in Abeokuta peri-urban, Ogun state, Southwestern Nigeria: The gender implications. The Journal of Gender and Water 2017;4:73-81.

59. Mercer N, Hanrahan M. "Straight from the heavens into your bucket": domestic rainwater harvesting as a measure to improve water security in a subarctic indigenous community. Int $J$ Circumpolar Health 2017;76:1312223.

60. Porter G, Hampshire K, Abane A, et al. Child Porterage and Africa's Transport gap: evidence from Ghana, Malawi and South Africa. World Dev 2012;40:2136-54.

61. Porter G, Hampshire K, Dunn C, et al. Health impacts of pedestrian head-loading: a review of the evidence with particular reference to women and children in sub-Saharan Africa. Soc Sci Med 2013;88:90-7.
62. IASP. IASP Taxonomy. 2012 www.iasp-pain.org (accessed 15Feb 2012)

63. Anderson KO. Role of cutpoints: why grade pain intensity? Pain 2005;113:5-6.

64. DeLoach LJ, Higgins MS, Caplan AB, et al. The visual analog scale in the immediate postoperative period: intrasubject variability and correlation with a numeric scale. Anesth Analg 1998;86:102-6.

65. Flaherty SA. Pain measurement tools for clinical practice and research. Aana J 1996;64:133-40.

66. Turk DC, Dworkin RH, Allen RR, et al. Core outcome domains for chronic pain clinical trials: IMMPACT recommendations. Pain 2003;106:337-45.

67. Crossley TF, Kennedy S. The reliability of self-assessed health status. J Health Econ 2002;21:643-58.

68. Lloyd R, Parr B, Davies S, et al. Subjective perceptions of load carriage on the head and back in Xhosa women. Appl Ergon 2010;41:522-9.

69. Jäger HJ, Gordon-Harris L, Mehring UM, et al. Degenerative change in the cervical spine and load-carrying on the head. Skeletal Radiol 1997;26:475-81.

70. Joosab M, Torode M, Rao PV. Preliminary findings on the effect of load-carrying to the structural integrity of the cervical spine. Surg Radiol Anat 1994:16:393-8.

71. Jumah KB, Nyame PK. Relationship between load carrying on the head and cervical spondylosis in Ghanaians. West Afr J Med 1994;13:181-2.

72. Kumaresan S, Yoganandan N, Pintar FA, et al. Contribution of disc degeneration to osteophyte formation in the cervical spine: a biomechanical investigation. J Orthop Res 2001;19:977-84.

73. Houten JK, Noce LA. Clinical correlations of cervical myelopathy and the Hoffmann sign. J Neurosurg Spine 2008;9:237-42.

74. Machino M, Yukawa Y, Hida T, et al. The prevalence of pre- and postoperative symptoms in patients with cervical spondylotic myelopathy treated by cervical laminoplasty. Spine 2012;37:E13838.

75. Román GC. Tropical myelopathies. Handb Clin Neurol 2014:121:1521-48.

76. Candy S, Chang G, Andronikou S. Acute myelopathy or cauda equina syndrome in HIV-positive adults in a tuberculosis endemic setting: MRI, clinical, and pathologic findings. AJNR Am J Neuroradiol 2014;35:1634-41.

77. Bhigiee Al, Madurai S, Bill PL, et al. Spectrum of myelopathies in HIV seropositive South African patients. Neurology 2001;57:348-51.

78. Dudler J, Balague $F$. What is the rational diagnostic approach to spinal disorders? Best Pract Res Clin Rheumatol 2002;16:43-57.

79. Magee DJ. Orthopedic Physical Assessment. 4th Edn. Philadelphia: Saunders, 2002

80. Maloiy GM, Heglund NC, Prager LM, et al. Energetic cost of carrying loads: have African women discovered an economic way? Nature 1986;319:668-9.

81. Heglund NC, Willems PA, Penta M, et al. Energy-saving gait mechanics with head-supported loads. Nature 1995;375:52-4.

82. Lloyd R, Parr B, Davies S, et al. No 'free ride' for African women: a comparison of head-loading versus back-loading among Xhosa women. S Afr J Sci 2010;106:5.

83. Bisung E, Elliott SJ. Psychosocial impacts of the lack of access to water and sanitation in low- and middle-income countries: a scoping review. J Water Health 2017;15:17-30.

84. Schatz E, Gilbert L. "My legs affect me a lot... I can no longer walk to the forest to fetch firewood": challenges related to health and the performance of daily tasks for older women in a high HIV context. Health Care Women Int 2014;35(7-9):771-88.

85. Wrisdale L, Mokoena MM, Mudau LS, et al. Factors that impact on access to water and sanitation for older adults and people with disability in rural South Africa: An occupational justice perspective. $J$ Occup Sci 2017:24:259-79.

86. Hallal PC, Victora CG, Azevedo MR, et al. Adolescent physical activity and health: a systematic review. Sports Med 2006;36:1019-30.

87. Beaglehole R, Bonita R, Kjellstrom T. Basic Epidemiology. Geneva: World Health Organisation, 1993.

88. Water and Sanitation for the Urban Poor (WSUP), Consortium SaHARfESR. Evaluating the health impact of urban WASH programmes: an affordable approach for enhancing effectivenes. Discussion Paper, 2011. 